\title{
Comentarios en torno a la presentación de la revista Intervención
}

\author{
Linda R. Manzanilla
}

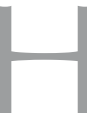

oy celebramos el surgimiento de un nuevo órgano de divulgación del conocimiento relativo a la conservación, la restauración y la museología. La revista Intervención llena un vacío, permite la transmisión de nuevos conocimientos científicos y técnicos en la materia, ofrece un espacio crítico de diálogo y discusión.

Es, sin duda, motivo de regocijo el inicio de un esfuerzo académico interdisciplinario que espero se consolide a través del tiempo y permita que los expertos mexicanos en los temas de la conservación, la restauración y la museología socialicen su quehacer a nivel internacional. Celebro asimismo que en el marco de la Escuela Nacional de Conservación, Restauración y Museografía del INAH, una escuela de estatura mundial, surja una iniciativa ambiciosa que confio se convierta en un órgano de excelencia.

Un punto que deseo resaltar, es la interesante propuesta estructural de la revista. Su diseño ofrece, como un prisma, múltiples facetas, escalas y niveles de análisis. Desde los más técnicos que se exponen en las secciones: "Informe" o "Reporte de campo", pasando por la sección "Investigación" que ofrece procedimientos nuevos en materia de conservación, hasta secciones sugerentes que invitan al debate y a la reflexión.

En varios aspectos, la conservación/restauración sigue una serie de pasos lógicos que Carolusa González Tirado aborda y que tienen semejanza con el quehacer arqueológico. Un primer aspecto consistiría en conocer la historia y la ubicación geográfica e histórica del objeto o sitio, para posteriormente contextualizarlo.

En segundo lugar, el conservador hace un diagnóstico de deterioros que podría equipararse a una prospección de superficie en el caso de la arqueología, y que sirve para planificar el estudio a profundidad del asentamiento.

El tercer paso residiría en la investigación de los materiales, técnicas de manufactura, uso y función del objeto, que en arqueología tiene su paralelismo cuando se excavan extensivamente las estructuras arquitectónicas; se analizan los materiales y técnicas constructivas; se estudian minuciosamente los pisos y sus áreas de actividad; se fechan los contextos y se establece la función a la cual fueron destinados los espacios.

El cuarto paso atañe a la interpretación. En este punto es de vital importancia que ésta se base en datos obtenidos de manera sistemática, rigurosa y con un trasfondo científico claro, con el fin de evitar, en lo posible, graves errores.

Pero la restauración va más allá, cuando tiene que decidir si retira porciones añadidas a la obra u objeto en tiempos posteriores a su manufactura original, 
o si debe reintegrar partes faltantes, es decir, modificar el objeto. Es en este punto cuando se deben constatar, paso a paso, las acciones emprendidas y los criterios utilizados para ello.

En sí, la conservación y la restauración yacen en la confluencia de arte, historia, ciencia y técnica. Requieren de conocimientos, destrezas, habilidad y también, de asumir una responsabilidad frente a la historia.

La contextualización del objeto y obra ofrece un ámbito rico que agrega información a la ya obtenida, al analizarlo en cuanto a sus materias primas, técnicas de manufactura y decoración. Las asociaciones contextuales del objeto permiten articularlo con otros que aportan información funcional.

Pondré un ejemplo: un vaso trípode de cerámica tiene contenidos funcionales distintos dependiendo del área de actividad en el que fue hallado. Si se encuentra en el taller del alfarero que lo produce y decora, aparecerá asociado a pigmentos, arcillas e instrumental del artesano, y no tendrá residuos de utilización en su interior. Probablemente se relaciona a un espacio de almacenamiento de productos terminados.

Un contenido funcional muy distinto se presentará si se encuentra el mismo vaso trípode como ofrenda de un entierro humano, y en el cual seguramente se hallarán trazas

\section{Nota del Editor}

El jueves 5 de agosto de 2010, en la Escuela Nacional de Conservación, Restauración y Museografía, se llevó a cabo la presentación de Intervención. Revista Internacional de Conservación, Restauración y Museología. Los discursos sobre la publicación periódica estuvieron a cargo de Miguel Ángel Echegaray, Secretario Técnico del Instituto Nacional de Antropología e Historia; Liliana Giorguli, Directora de la ENCRyM; $y$, de Isabel Medina, editora del número inaugural de la revista. Para comentar este primer número de Intervención se invitó a Linda Rosa Manzanilla Naim, investigadora del Instituto de Investigaciones Antropológicas de la UNAM y a Héctor Rivero Borrell, director del Museo Franz Mayer.

Como un apreciable gesto de amabilidad, la doctora Manzanilla ha permitido la publicación de sus comentarios en este segundo número de Intervención.

Este texto cumple con distintas funciones. Es una interesante reseña del contenido del primer número de la revista, y refleja el júbilo experimentado al ver materializado un esfuerzo académico. Por otra parte, contribuye a ampliar la discusión presentada en la sección Debate, del número inaugural de Intervención. En este sentido consideramos que los comentarios expresados por Linda Rosa Manzanilla enriquecen el intercambio de opiniones, al ofrecer una visión diferente desde el punto de vista de la arqueología, con un valor añadido por el hecho de provenir de una investigadora acostumbrada a trabajar de manera interdisciplinaria con restauradores. macroscópicas o microscópicas del contenido. Estará entonces relacionado no sólo a restos óseos humanos, sino que su ubicación, asociación con otras ofrendas y decoración, nos revelarán el escenario simbólico del ámbito funerario de la civilización estudiada.

Otro contenido funcional diverso es el caso del mismo vaso trípode "matado" en un ritual de terminación. En este caso la manera de golpear el vaso, sea estrellándolo contra el piso o pared, o bien golpeándolo con una piedra; puede ser identificada al hacer un registro minucioso de tipo espacial de los diversos fragmentos del vaso trípode.

En ocasiones, hemos afrontado juntos, restaurador y arqueólogo, la decisión de dejar visible la oquedad del acto ritual de "matar" simbólicamente una pieza cerámica, ya que el hueco provee información que la vasija completa no transmite. Así, en ciertos casos teotihuacanos que hemos trabajado conjuntamente en la Escuela Nacional de Conservación, Restauración y Museografía del INAH se ha dispuesto un acrílico transparente en el hueco, con el fin de permitir la visión del espacio y no poner en riesgo la estabilidad de la pieza.

Por tanto, la contextualización del objeto permite asumir un esfuerzo de conservación y restauración diferenciado según el caso. Asimismo, supongo que los agentes de deterioro cambiarán dependiendo de si éste se encuentra

Sin proponérselo, Linda Rosa Manzanilla presenta una tercera réplica al Debate planteado en el número uno de Intervención, de una manera espontánea y fresca. En ésta surgen comentarios que definen la manera en la que otros profesionistas conciben la labor del restaurador. A manera de ejemplo, baste mencionar aquella parte en la que Manzanilla acertadamente señala que la restauración requiere asumir una responsabilidad frente a la historia. Algunas frases en el comentario de Manzanilla denotan que han quedado atrás los tiempos en los que el restaurador era considerado como un técnico, un operario que se limitaba a ejecutar las indicaciones del arqueólogo; se ha superado también la etapa en la que el restaurador dogmático, celoso y orgulloso de sus saberes, tomaba decisiones basadas en la condición material del objeto, sin consultar con otros especialistas. Es un halago a la profesión, y síntoma de su madurez, el hecho que alguien de la talla de Manzanilla, quien recientemente fue distinguida con un doctorado honoris causa por la UNAM, señale el trabajo conjunto del restaurador y arqueólogo en la toma de decisiones acerca del patrimonio cultural. A lo largo del texto podemos apreciar una comparación entre la epistemología de la arqueología y la de la restauración, señalando similitudes y discrepancias, con la intención de resaltar que ambas operan al mismo nivel en cuanto a sus fundamentos y métodos.

Para aquellos lectores de este segundo número de Intervención que no han tenido oportunidad de leer el número inaugural, sirva este texto como reseña de sus principales secciones. Para quienes han leído el "Debate" presentado en el número anterior, ofrecemos un tercer punto de vista. 


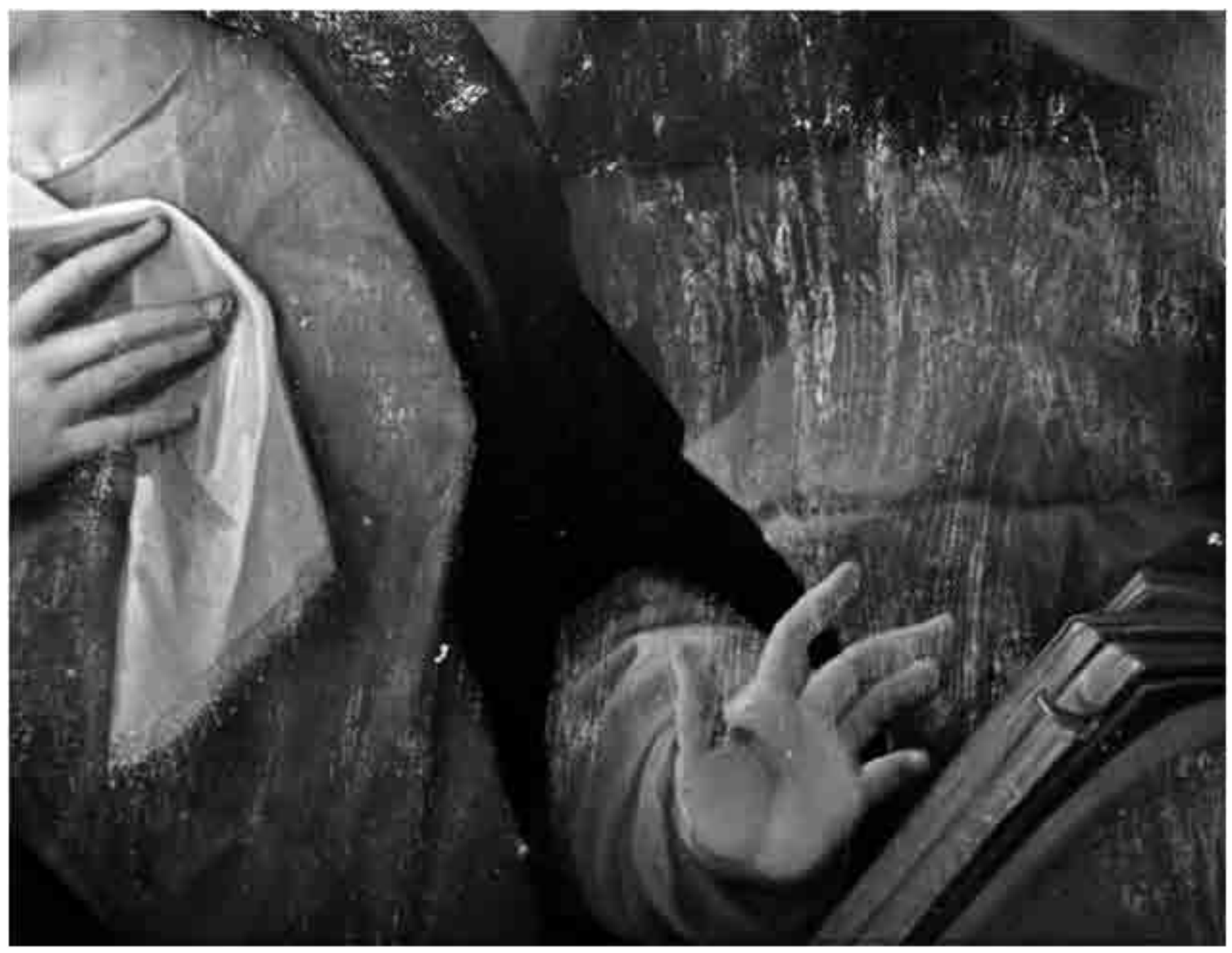

en un almacén, un entierro o un ritual de terminación. Es así que un trabajo articulado entre arqueólogo y restaurador permitirá abrir un abanico de opciones más amplio en cuanto a las acciones tomadas sobre el objeto u obra.

Un aspecto debatible es sin duda el de la limpieza de los objetos. Carolusa González Tirado Ilama la atención acerca de la doble cara de la pátina: una capa protectora versus un proceso continuo de deterioro. Tres posibilidades se abren al paso: la primera sería dejar los objetos sin limpiar, lo cual conlleva el riesgo de que la pieza se deteriore irremediablemente; la segunda sería limpiarla totalmente, creando así una contradicción y discordancia histórica; y la tercera sería la limpieza selectiva. En este último caso, tendrían que explicitarse los criterios que fueron asumidos para eliminar ciertos rastros de deterioro y dejar otros. Si bien los cánones prescriben que se deben eliminar suciedades y productos de alteración que desfiguren la apariencia del objeto, dejando así únicamente la pátina; hay trazas producto del uso o función a la cual fue destinado el objeto que pueden ser confundidos con suciedad, perdiendo así información sobre el contenido de recipientes, por ejemplo. Por tanto, es importante asu- mir una estrategia analítica de tipo científico para añadir al diagnóstico de los agentes de deterioro, la información sobre otras trazas visibles que son parte de la historia funcional del objeto.

Como González Tirado señala, una restauración inadecuada causa pérdida de información, y esta situación es paralela a una excavación inadecuada y sin el registro pertinente. Como señaló el arqueólogo Mortimer Wheeler, la excavación es como leer un manuscrito único del cual arrancamos las páginas y las destruimos. Si no registramos conveniente y exhaustivamente lo que vamos hallando, perderemos irremediablemente datos únicos.

Aspecto polémico es sin duda el que el restaurador deba asumirse como artista-intérprete. ¿Cómo acotar los pensamientos subjetivos sobre la obra u objeto, y someterlo a una batería de acciones lógicas de intervención?

La réplica de Salvador Muñoz Viñas a la premisa: "El restaurador como artista-intérprete" menciona que la restauración depende en buena medida de juicios que no son científicos, que no son objetivables. Sin embargo, precisamente debido a la gran responsabilidad que conllevan pensamientos subjetivos aplicados sobre obras con 
contenido histórico, objetos que son únicos, es necesario establecer criterios claros y acotar el ámbito subjetivo. No basta con el principio ético de la reversibilidad que permitiría desarticular lo armado erróneamente, o eliminar lo perjudicial a la obra. La premisa del restaurador como recreador debe estar acotada con criterios claros, acciones sucesivas y organizadas en protocolos que tengan el consenso de la mayoría de los restauradores. Subrayo la noción de que las intervenciones sobre las obras u objetos del pasado requieren de decisiones colectivas, no individuales; de un acercamiento interdisciplinario para ver el objeto desde diversas ópticas; de un trabajo en equipo, más que de un esfuerzo individual.

Sin querer abonar a una polémica interminable, sólo diré que la frase: "el restaurador no debería imponer su gusto artístico, o su noción estética personal, sino la que resultará más satisfactoria para más personas y durante más tiempo", es una idea difícil de ponderar. Las obras del pasado están destinadas a ser patrimonio de la humanidad y a perdurar en el futuro. ¿Qué parámetros estéticos son compartidos por muchas culturas y pueblos? El ámbito estético del restaurador y del público que admirará la obra o el objeto son problemas espinosos.

Valerie Magar basa su réplica en la responsabilidad del conservador/restaurador frente a las intervenciones. Los ejemplos que cita son esclarecedores: las reconstrucciones de pintura y arquitectura en la capital de los minoicos; o bien, la escasa atención que se ha dado a la esencia polícroma de las esculturas marmóreas de Grecia y Roma; o bien, la forma y dimensiones de la Pirámide del Sol después de las intervenciones de Leopoldo Batres a principios del siglo $x x$.

Valerie Magar llama la atención sobre los temas de percepción y presentación: juicio crítico, formación y capacitación de conservadores, y ampliación de grupos de interés. $Y$ en la formación de jóvenes propone que el juicio crítico sea el núcleo alrededor del cual graviten la destreza; los conocimientos de técnicas, materiales, evolución y envejecimiento de materiales; la sensibilidad hacia el contexto histórico, artístico y social de la obra; y la ética de la conservación. Un punto interesante que Magar invoca es la interacción del público con el restaurador, durante el proceso mismo de intervención del edificio, el objeto o la obra.

En la sección "Ensayo", Luis Gerardo Morales aborda el tema de los museos de historia, y cómo se comunica la es- critura de la historia de manera diversa, a través de la escenificación visual, desde el discurso de pasados prehispánicos que convergen en un glorioso ámbito mexica, petrificado en monolitos gigantescos que Ilenan la sala azteca del Museo de Antropología, situada en el centro y fondo, opuesto al ingreso; hasta la épica de los museos de historia y su vinculación con el ámbito escolar. Escenario de la transmisión popular de la historia, no sólo de fechas, actores y acontecimientos, sino la reproducción de ritos conmemorativos, que yacen en la base de la identidad nacional. Así, causas, evidencias, explicaciones y formas de representación están hiladas, pero rara vez proveen de visiones críticas y alternativas de interpretación.

Michael Schiffer hablaba de transformaciones culturales del contexto arqueológico, como la "recuperación", el "reciclaje" y el "reuso"; en la primera de estas transformaciones culturales, los objetos arqueológicos $\mathrm{O}$, para nuestro caso, históricos, transitan de un tiempo de uso en la sociedad que los produjo a otro tiempo en que una nueva los observa y admira, por ejemplo, en los museos. Esta descontextualización requiere de una traducción interpretativa.

En la sección "Diálogos", Ana Garduño Ortega pone sobre la mesa al objeto: los títeres de Rosete Aranda, y a su restaurador: Sergio Montero, un ícono de la materia en México, así como un creador de muñecos y escenarios. ¿Quién mejor que él?

Como "Investigación" se presenta el trabajo de Jannen Contreras Vargas, una plataforma crítica del uso de la tiourea para la limpieza de bienes culturales en plata. Al desgajar rutinas que los varios restauradores reprodujeron muchas veces, Jannen Contreras Ilama la atención sobre el deterioro por microfisuras que produjo el empleo de la tiourea en ciertas obras, la deposición de sulfuros; la alteración de la apariencia por la disolución de la plata, del mercurio, del cobre e incluso del oro, produciendo así daños irreversibles, amén del efecto que el proceso puede ocasionar sobre el ser humano.

La voz de los estudiantes y profesores también está presente en esta revista, a través de una evaluación de las prácticas de campo y la ponderación de los alcances de la especialidad en conservación de fotografías.

Como dije en un inicio, la revista Intervención sugiere un prisma de facetas distintas, de perspectivas críticas así como de planteamientos novedosos, donde voces diversas tienen un nuevo foro, que espero conserve el sello de excelencia. 